\title{
PEMANFAATAN LAYANAN BIMBINGAN KELOMPOK UNTUK MENINGKATKAN KECERDASAN EMOSI SISWA
}

\author{
Yola Ulandari ${ }^{1}$ dan Dosi Juliawati ${ }^{2}$ \\ ${ }^{1,2}$ Institut Agama Islam Negeri (LAIN) Kerinci \\ e-mail:dosi@konselor.org
}

\begin{abstract}
This research background is an indication of students 'intelligence that is still low and needs to be improved, so this study aims to improve students' emotional intelligence through group guidance services through an experimental approach with the design of the one group pretest-posttest design. The research sample was 10 people selected through purposive sampling technique. Data was revealed through a Likert scale model questionnaire and analyzed using the Wilcoxon Signed Ranks Test. The results showed that there was a significant effect after being given group guidance services to students' emotional intelligence.
\end{abstract}

Keywords: Guidance, Group, Intelligence, Emotion

\begin{abstract}
Abstrak. Latar belakang penenlitian ini yaitu adanya indikasi kecerdasan siswa yang masih rendah dan perlu untuk ditingkatkan, sehingga penelitian ini ubertujuan untukmeningkatkan kecerdasan emosi siswa melalui layanan bimbingan kelompok melalui pendekatan eksperimen dengan rancangan the one group pretest-posttest design. Sampel penelitian sebanyak 10 orang yang dipilih melalui teknik purposive sampling. Data diungkap melalui angket model skala likert dan dianalisis menggunakan uji Wilcoxon Signed Ranks Test. Hasil penelitian menunjukkan bahwa terdapat pengaruh yang signifikan setelah diberikan layanan bimbingan kelompok terhadap kecerdasan emosi siswa.
\end{abstract}

Kata Kunci: Bimbingan, Kelompok, Kecerdasan, Emosi

\section{PENDAHULUAN}

Dalam kehidupan sehari-hari, manusia tidak bisa memisahkan dirinya dari emosi. Emosi merupakan aliran energi yang ada di dalam manusia yang diciptakan oleh Allah SWT agar bisa menjalankan tugas penting dalam kehidupan ini dan untuk menyempurnakan kehidupan manusia (Yandri, 2017). Emosi merujuk pada suatu perasaan dan pikiran yang khas, suatu keadaan biologis dan psikologis dan serangkaian kecenderungan untuk bertindak 
(Goleman dalam Riyanto, 2010). Emosi merupakan salah satu kekuatan yang dimilki oleh manusia untuk mampu meraih kesuksesan, salah satunya kesuksesan belajar. Kesuksesan belajar peserta didik yang berada pada masa remaja mengalami masa transisi yang akan banyak mengalami masalah perkembangan (Santrock, 2003; Yandri \& Juliawati, 2018 ) seperti masalah psikologis, fisiologis dan sehingga mudah terjadinya kegelisahan, masalah, dan stres pada remaja yang lebih disebabkan oleh pengaruh lingkungan yang kurang memperhatikan, menyokong, menghargai, mengakui, dan mendampingi mereka yang sedang berkembang (Elida, 2006).

Masalah yang dialami oleh peserta didik pada masa remaja akan mengganggu kondisi emosinya, jika emosi yang dialami oleh peserta didik dalam belajar buruk atau negatif, maka akan menganggu proses belajar (Djaali, 2011) tentunya hal ini akan merugikan peserta didik. Sehingga dalam proses belajar yang harus dikembangkan yaitu emosi positif, namun tidak semua peserta didik mampu memilki kecerdasan dalam mengelola emosinya dengan bijak. Orang-orang yang mampu mengelola emosinya dengan baik disebut memilki kecerdasan emosi yang baik. Kecerdasan emosi merupakan keterampilan yang mampu membuat hidup seseorang menjadi lapang dari aspek pribadi, sosial, dan pertahanan pribadi (Stein \& Howard, 2003). Orang yang cerdas secara emosi memungkinkan dirinya mampu menggunakan dan memanfaatkan emosinya dengan baik dan benar (Yandri \& Juliawati, 2018).

Studi awal yang peneliti lakukan pada siswa di Sekolah Menengah Pertama Negeri (SMPN) 12 Sungai Penuh mengindikasikan adanya siswa yang memiliki kecerdasan emosi rendah seperti adanya siswa kurangnya kemampuan dalam mengenali perasaan sendiri dan perasaan orang lain, rendahnya kemampuan mengendalikan emosi serta rendahnya kemampuan beradaptasi dengan lingkungan. Selanjutnya ada siswa sulit menerima kritik dan saran dari orang lain, ada siswa yang sulit mengendalikan diri dan sulit bergaul dengan temantemannya karena kurang dapat berkomunikasi dengan orang lain, serta ada siswa yang menghindar dari masalah karena merasa cemas dan ketakutan. Kemudian dari hasil penelitian yang dilakukan oleh Yandri (2017) mengungkapkan bahwa sebelum melakukan eksperimen dirasah pengembangan diri melalui pelayanan konseling, ada mahasantri Ma'had Al Jami'ah IAIN Kerinci memiliki kecerdasan emosi yang rendah. Jika kecerdasan peserta didik tidak dibantu dikembangkan, maka besar kemungkinan akan menggangu proses belajarnya di sekolah.

Sehingga, pengembangan kecerdasan emosi peserta didik perlu dibantu oleh orang dewasa, salah satunya yaitu oleh guru BK di sekolah. Salah satu tugas guru BK di sekolah yaitu memfasilitasi perkembangan peserta didik agar perkembangan peserta didik menjadi optimal 
(Juliawati, 2016) dengan memanfaatkan 10 layanan yang menjadi tugas tanggungjawabnya. Salah satu layanan BK yang bisa di manfaatkan yaitu layanan bimbingan kelompok. Layanan bimbingan kelompok merupakan kegiatan tatap muka antara pemimpin kelompok (Konselor) dengan anggota kelompok yang memanfaatkan dinamika kelompok untuk membahas suatu topik bahasan yang bermanfaat bagi anggota kelompok dengan tujuan untuk pengembangan kemampuan bersosialisasi khususnya kemampuan berkomunikasi peserta layanan serta dapat mendorong mendorong pengembangan nilai rasa, pemikiran, persepsi, wawasan dan pengetahuan, dan serta sikap untuk mewujudkan tingkah laku yang lebih efektif (Juliawati, 2014). Dalam layanan bimbingan kelompok, aktivitas, dan dinamika kelompok harus diwujudkan untuk membahas berbagai hal yang berguna untuk pengembangan atau pemecahan masalah individu yang menjadi peserta layanan (Tohirin, 2011).

Untuk itu, perlu dilakukan penelitian untuk mengungkap kecerdasan emosi siswa serta perlu adanya penanggulangan yang tepat sehingga kecerdasan emosi siswa menjadi lebih baik. Asumsi peneliti, kecerdasan siswa yang rendah bisa ditingkatkan dengan memanfaatkan layanan bimbingan kelompok, sehingga tujuan penelitian ini yaitu untuk mengungkapkan efektivitas layanan bimbingan kelompok dalam meningkatkan kecerdasan emosi siswa.

\section{METODE}

Metodologi penelitian ini menggunakan penelitian kuantitatif eksperimen dengan rancangan one group pretest-posttest. design dengan memberikan pretest kepada kelompok eksperimen sebelum perlakuan dilakukan dan setelah perlakuan dilakukan, diberikan posttest guna melihat perbandingan hasil sebelum dengan sesudah perlakuan diberikan (Yusuf, 2013). Responden penelitian ini yaitu siswa Sekolah Menengah Pertama Negeri (SMPN) 12 Sungai Penuh berjumlah 10 orang yang diambil dengan metode purposive sampling. Data penelitian dikumpulkan dengan menggunkan angket model skala likert yang divalidasi oleh para ahli di bidang bimbingan dan konseling. Analisis data dalam peneltian ini menggunakan skor ideal (Azwar, 2010) dan menggunakan statistik non parametrik dengan asumsi data yang kurang dari 30 tidak berdistribusi normal dengan memanfaatkan uji jenjang bertanda Wilcoxon (signed ranks test) karena peneliti ingin melihat kepastian tentang ada atau tidaknya perbedaan kondisi kecerdasan emosi siswa setelah perlakuan diberikan (Santoso, S, 2012; Yandri, 2017). 


\section{HASIL}

Temuan penelitian ini menjelaskan bahwa terdapat pengaruh yang signifikan terhadap kecerdasan emosi pada siswa setelah diberikan perlakuan layanan bimbingan kelompok. Kecerdasan emosi merupakan salah satu penentu keberhasilan siswa dalam belajar sehingga perlu adanya kegiatan peningkatan dan pengembangan kecerdasan emosi siswa ke arah yang lebih baik agar potensi yang dimilki siswa bisa berkembang dengan optimal. Sesuai dengan tujuan dilakukannya pretest, yaitu untuk mengetahui gambaran awal kondisi kecerdasan emosi siswa sebelum diberikan perlakuan

Berikut ini dijelaskan gambaran kecerdasan emosi siswa sebelum dilakukannya perlakuan berupa layanan bimbungan kelompok yang bisa dilihat pada tabel berikut.

Tabel 1. Hasil Pretest Kecerdasan Emosi Siswa

\begin{tabular}{cccc}
\hline Kategori & Rentang Skor & Frekuensi & Persentase \\
\hline Sangat Rendah & $\leq 128$ & 2 & 20 \\
\hline Rendah & $128>$ s.d $\leq 143$ & 1 & 10 \\
\hline Sedang & $143>$ s.d $\leq 159$ & 4 & 40 \\
\hline Tinggi & $159>$ s.d $\leq 174$ & 3 & 30 \\
\hline Sangat Tinggi & $174>$ & 0 & 0 \\
\hline & Jumlah & 10 & 100 \\
\hline
\end{tabular}

Dari tabel di atas, bisa dijelaskan bahwa kondisi kecerdasan emosi siswa tergolong masih rendah dengan hasil rata-rata skor kelompok yaitu 149,5. Hal ini menunjukkan bahwa, masih ada siswa dalam kelompok eksperimen yang memliki kecerdasan emosi yang rendah.

Kemudian, penjelasan gambaran kecerdasan emosi siswa setelah dilakukannya perlakuan berupa layanan bimbungan kelompok yang bisa dilihat pada tabel beikut

Tabel 2. Hasil Posttest Kecerdasan Emosi

\begin{tabular}{cccc}
\hline Kategori & Rentang Skor & Frekuensi & Persentase \\
\hline Sangat Rendah & $\leq 128$ & 0 & 0 \\
\hline Rendah & $128>$ s.d $\leq 143$ & 0 & 0 \\
\hline Sedang & $143>$ s.d $\leq 159$ & 0 & 0 \\
\hline Tinggi & $159>$ s.d $\leq 174$ & 2 & 20 \\
\hline Sangat Tinggi & $174>$ & 8 & 80 \\
\hline & Jumlah & 10 & 100
\end{tabular}

Pada tabel 2, bisa dijelaskan bahwa kondisi kecerdasan emosi siswa sudah mengalami perbaikan dengan kategori sangat tinggi, hal ini dibuktikan dengan hasil rata-rata skor kelompok yaitu 193,3. Hal ini menunjukkan bahwa, setelah diberikan perlakuan berupa layanan bimbingan kelompok kecerdasan emosi siswa menjadi lebih baik.

Hasil penelitian menujukkan bahwa terdapat perbedaan kecerdasan emosi pada siswa sebelum diberikan perlakuan (Pretest) dan sesudah diberikan perlakuan (Posttest) berupa layanan 
bimbingan kelompok. Kondisi kecerdasan emosi siswa pada saat pretest berada pada skor ratarata 149,5 setelah diberi perlakuan berupa layanan bimbingan kelompok, skor rata-rata kelompok naik menjadi 193,3, sehingga terjadi peningkatan kecerdasan emosi siswa sebanyak 29,30\%. Kemudian untuk melihat peningkatan skor per responden, bisa dilihat pada tabel 3 berikut:

Tabel 3. Kondisi Kecerdasan Emosi Siswa pada Saat Pretest dan Posttest

\begin{tabular}{cccccc}
\hline \multirow{2}{*}{ No. } & Kode Siswa & \multicolumn{2}{c}{ Pretest } & \multicolumn{2}{c}{ Posttest } \\
\cline { 2 - 5 } & & Skor & Kategori & Skor & Kategori \\
\hline 1 & NZHN & 123 & Sangat Rendah & 170 & Tinggi \\
\hline 2 & AF & 153 & Tinggi & 187 & Sangat Tinggi \\
\hline 3 & PE & 127 & Sangat Rendah & 171 & Tinggi \\
\hline 4 & ANA & 156 & sedang & 195 & Sangat Tinggi \\
\hline 5 & DA & 170 & tinggi & 204 & Sangat Tinggi \\
\hline 6 & GW & 143 & Rendah & 204 & Sangat Tinggi \\
\hline 7 & RM & 158 & Tinggi & 190 & Sangat Tinggi \\
\hline 8 & DAF & 152 & sedang & 191 & Sangat Tinggi \\
\hline 9 & SK & 158 & sedang & 211 & Sangat Tinggi \\
\hline 10 & NC & 155 & sedang & 207 & Sangat Tinggi \\
\hline
\end{tabular}

Selanjutnya hasil uji statistik dengan menggunakan analisis Wilcoxon Signed Rank Test bisa dilihat pada tabel berikut:

Tabel 4. Hasil Analisis Wilcoxon Signed Rank Test

\begin{tabular}{c|c}
\hline & Posttest - Pretest \\
\hline$Z$ & $-2.807^{\mathrm{a}}$ \\
\hline Asymp. Sig. (2-tailed) & .005 \\
\hline
\end{tabular}

Hasil uji statistik non parametik dengan rumus Wilcoxon Signed Rank Test yang menunjukkan angka probabilitas Sig (2- Tailed) kecerdasan emosi yang dimiliki siswa sebesar 0,005 atau probabilitas di bawah alpha 0,05 $(0,005<0,05)$, dari hasil tersebut maka Ho ditolak dan Ha diterima. Dengan demikian, hipotesis yang diuji dalam penelitian dapat diterima yaitu terdapat pengaruh yang signifikan terhadap kecerdasan emosi pada siswa setelah diberikan perlakuan layanan bimbingan kelompok.

\section{PEMBAHASAN}

Hasil penelitian sebelum dilakukan perlakuan pada responden menunjukkan skor rata-rata peroleh responden yaitu 149,5 pada saat pretest. Hal ini menunjukkan bahwa masih ada siswa yang memilki keterampilan dalam mengelola emosi yang kurang baik. Emosi merupakan suatu kekuatan yang dapat mengalahkan nalar, maka harus ada upaya untuk mengendalikan, mengatasi dan mendisiplinkan kehidupan emosional, dengan memberlakukan gejolak emosi, 
terutama nafsu yang terlampau bebas dalam diri anak-anak akan membantu mereka mengambil keputusan dan dapat menilai mana sesuatu yang harus dilakukan dan mana yang tidak boleh dilakukan (Aunurrahman, 2009). Orang-orang yang cerdas secara emosi memiliki kemampuan utama mengenali emosi diri dengan baik, memilki kesadaran diri, mengelola emosi dengan bijak, memotivasi diri, pengaturan diri, mengenali emosi orang lain dan mampu membina hubungan sosial yang baik dengan orang lain (Goleman dalam Yandri, 2017; Andriani, 2014).

Kecerdasan emosi merupakan sejumlah kemampuan mengenali emosi diri sendiri, mengelola dan mengekspresikan emosi diri sendiri dengan tepat, memotivasi diri sendiri, mengenali orang lain, dan membina hubungan dengan orang lain. Sedangkan faktor yang mempengaruhi kecerdasan emosional siswa antara lain adalah mengenali emosi diri/ kesadaran diri, mengelola emosi, memotivasi diri sendiri, mengenali emosi orang lain dan membina hubungan dengan orang lain (Prawira, 2016). Sebaliknya, siswa yang mengalami gangguan emosi bisa jadi karena persepsi yang tidak benar dan pikiran yang irasional, yang disadari maupun tidak disadari akan masalah-masalah yang menimpanya serta merasa kebutuhan fisik tidak terpenuhi, tidak mendapatkan kasih sayang, merasa tidak mampu (bodoh), merasa tidak senang dengan kehidupan keluarga, merasa menderita dan iri yang mendalam terhadap orang lain (Ellis dalam Sobur, 2009; Elida, 2006).

Setelah dilakukan perlakuan berupa bimbingan kelompok, skor rata-rata perolehan responden menjadi 193,3 pada saat posttest. Kemudian dari hasil uji Wilcoxon Signed Rank Test menunjukkan probilitas Sig (2-tailed) kecerdasan emosi siswa sebesar 0,005 atau probilitas di bawah alpha $0,05(0,005<0,05)$ dari hasil tersebut maka Ho ditolak dan Ha diterima. Dengan demikian, maka hipotesis yang diuji dalam penelitian ini dapat diterima, yaitu "Terdapat perbedaan yang signifikan pada kecerdasan emosi siswa setelah diberi perlakuan berupa bimbingan kelompok.". Layanan bimbingan kelompok bisa dimanfaatkan oleh siswa sebagai wahana menambah pengetahuan siswa dalam menggali informasi tertentu dan anggota kelompok (siswa) dapat belajar dari pengalaman-pengalaman anggota kelompok lainnya (Yandri, 2017).

Hal ini menjelaskan bahwa adanya pengaruh layanan bimbingan kelompok terhadap kecerdasan emosi siswa yang menjadi lebih baik. Dalam menigkatkan kecerdasan emosional, guru BK memberikan andil yang cukup besar dalam menambah pengetahuan siswa tentang cara mengenali diri/kesadaran diri, cara mengelola emosi, cara memotivasi diri, cara mengenali emosi orang lain dan cara membina hubungan dengan orang lain. Melalui proses kegiatan layanan bimbingan kelompok, siswa menjadi terbuka dan antusias serta aktif dalam mengikuti 
setiap tahap dalam bimbingan kelompok sehingga suasana kelompok menjadi hidup dan tidak membosankan dan juga melalui kegiatan layanan ini dapat melatih siswa untuk menyampaikan pendapatnya didepan umum (Juliawati, 2014). Dalam layanan bimbingan kelompok, aktivitas, dan dinamika kelompok harus diwujudkan untuk membahas berbagai hal yang berguna untuk pengembangan atau pemecahan masalah individu yang menjadi peserta layanan (Tohirin, 2011). Kegiatan bimbingan kelompok sangat penting bagi siswa, karena melalui kegiatan bimbingan kelompok siswa dapat memperoleh pemahaman tentang nilai-nilai, sikap, dan pemecahan masalah serta keterampilan yang dapat dikembangkan dalam mengelola emosinya menjadi lebih baik lagi (Yandri, 2017).

\section{SIMPULAN}

Simpulan hasil penelitian yang telah dilakukan yaitu (1) gambaran kecerdasan emosi siswa sebelum diberi perlakuan berada pada kategori rendah, (2) gambaran kecerdasan emosi siswa setelah diberi perlakuan berada pada kategori tinggi, (3) terdapat pengaruh yang signifikan terhadap kecerdasan emosi pada siswa setelah diberikan perlakuan layanan bimbingan kelompok. Saran hasil penelitian ini ditujukan pada guru BK agar terus memanfaatkan layanan bimbingan kelompok di sekolah kepada siswa agar siswa mendapat pelayanan yang optimal dalam arang mengembangkan kecerdasan emosi siswa dan kepada peneliti selanjutnya untuk dapat melakukan penelitian dengan memanfaatkan layanan bimbingan konseling untuk jenis variabel lainnya.

\section{REFERENSI}

Andriani, A. (2014). Kecerdasan Emosional (Emotional Question) dalam Peningkatan Prestasi Belajar. Jurnal Ilmiah Didaktika, 2(1): 459-472

Aunurrahman. (2009). Belajar dan Pembelajaran. Bandung: Alfabeta

Azwar, S. (2010). Penyusunan Skala Psikologi. Yogyakarta: Pustaka Pelajar.

Elida, P. 2006. Psikologi Perkembangan Remaja. Padang: Angkasa Raya.

Juliawati, D. (2014). Efektivitas Layanan Bimbingan Kelompok Mengurangi Prokrastinasi Akademik Siswa. International Guidance and Counseling Conferrence, At Padang, West Sumatera, Indonesia. From https://www.researchgate.net/publication/327915616_ EFEKTIVITAS_LAYANAN_BIMBINGAN_KELOMPOK_MENGURANGI_PR OKRASTINASI_AKADEMIK_SISWA

Juliawati, D. (2016). Peran Guru Bimbingan dan Konseling/Konselor dalam Mengurangi Tingkat Prokrastinasi Akademik Siswa di Sekolah. Tarbawi: Jurnal Ilmu Pendidikan, 1(2). 
Prawira, P. A. (2016). Psikologi Pendidikan dalam Perspektif Baru. Jakarta : Ar-Ruuzz Media

Riyanto, Y. (2010). Paradigma Baru Pembelajaran. Jakarta : Kencana.

Santoso, S. (2012). Aplikasi SPSS pada Statistik Nonparametrik. Jakarta: Alex Media Komputindo

Santrock, J. W., (Ed). (2003). Adolescence: Perkembangan Remaja. Terjemahan Adelar, Shinto B \& Saragih, Sherly. Jakarta: Erlangga.

Sobur, A. (2009). Psikologi Umum. Bandung: Pustaka Setia

Tohirin, (2011). Bimbingan dan Konseling di Sekolah dan Madrasab (Berbasis Integrasi). Jakarta : Raja Grafindo Persada.

Yandri, H. (2016). Penerapan Sugesti pada Layanan Konseling Perorangan dalam Mengurangi Perilaku Merokok pada Siswa di Sekolah. Tarbawi: Jurnal Ilmu Pendidikan, 1(2).

Yandri, H. (2017). Efektivitas Dirasah Pengembangan Diri Melalui Pelayanan Konseling dalam Membentuk Kecerdasan Emosi Mahasantri Ma'had Al Jami’ah IAIN Kerinci. Tarbawi: Jurnal Ilmu Pendidikan, 13(1), 1-10.

Yandri, H., \& Juliawati, D. (2018). Profile of the Problem of the Adolescent with Parents as Indonesian Migrant Workers. Konselor, 7(4), 160-165.

Yusuf, A. M. (2013). Metodologi Penelitian: Kualitatif, Kuantitatif, dan Penelitian Gabungan. Padang : UNP Press. 